\title{
DISTRIBUIÇÃO ESPACIAL DO ÍNDICE REGIONAL DO CRÉDITO RURAL PARA O PARANÁ $(2008-2018)$
}

Spatial distribution of the Paraná State rural credit regional index (2008 - 2018)

DOI: 1048075/igepec.v26i1.28154

Juliana Karina Feil Gaffuri

Lucir Reinaldo Alves 


\title{
DISTRIBUIÇÃO ESPACIAL DO ÍNDICE REGIONAL DO CRÉDITO RURAL PARA O PARANÁ (2008-2018)'
}

\author{
Spatial distribution of the Paraná State rural credit regional index (2008-2018)
}

\author{
Juliana Karina Feil Gaffuri \\ Lucir Reinaldo Alves \\ DOI:10.48075/igepec.v26i1.28154
}

\begin{abstract}
Resumo: O objetivo desse artigo foi analisar a distribuição espacial do crédito rural em relação ao valor adicionado bruto da agropecuária para os municípios do Paraná, utilizando o Índice Regional do Crédito Rural (IRCR), para os anos de 2008, 2013 e 2018. Além disso, o estudo verificou a existência de correlação espacial do crédito rural e do VAB, a partir da Análise Exploratória de Dados Espaciais (AEDE). Os resultados mostraram que o Paraná teve um IRCR maior que a unidade em todo o período de análise, evidenciando que sua participação no crédito rural estava acima da sua participação no VAB. Foram identificadas desigualdades na distribuição espacial do crédito rural, o qual concentrou-se entre os municípios com maiores IRCR. A AEDE apresentou autocorrelação espacial positiva entre as variáveis, indicando que os municípios com elevada participação no crédito rural são vizinhos de municípios com elevada participação no valor adicionado bruto da agropecuária, com destaque para associações entre os municípios das mesorregiões Oeste, Centro-Ocidental, Norte-Central, Centro-Sul e Centro-Oriental Paranaense.
\end{abstract}

Palavras-chave: Crédito Rural. Valor Adicionado Bruto da Agropecuária. Índice Regional do Crédito Rural. Desenvolvimento.

\begin{abstract}
The aim of this paper was to analyse the spatial distribution of rural credit in relation to the agriculture gross added value of the Paraná State's municipalities, using as methodology the Regional Index of Rural Credit (RIRC), for the years 2008, 2013 and 2018. In addition, the study intends to evaluate the evolution of the distribution and the spatial concentrations of rural credit, and to verify if there is a spatial correlation of rural credit and the agriculture gross added value between the municipalities, based on the Exploratory Spatial Data Analysis (ESDA). The results showed that Paraná State had an RIRC higher than the unit in the entire period, showing that its participation in rural credit was above its participation in the agriculture gross added value. Inequalities were identified in the spatial distribution of rural credit, which was concentrated among the municipalities with the highest RIRC. The ESDA showed positive spatial autocorrelation between the variables, indicating that the municipalities with a high participation in rural credit are neighbours of municipalities with a high participation in the agriculture gross added value, with emphasis on associations between the municipalities in the Oeste, Centro-Ocidental, Norte-Central, Centro-Sul and Centro-Oriental Paranaense mesoregions.
\end{abstract}

Keywords: Rural credit. Agriculture Gross Added Value. Regional Rural Credit Index. Development.

\footnotetext{
${ }^{1}$ Trabalho selecionado no $59^{\circ}$ Congresso da SOBER ocorrido em Brasília de 2 a 6 de agosto de 2021. Grupo de Trabalho (GT): 07 - Desenvolvimento Rural, Territorial e Regional.
}

Informe GEPEC, ISSN:1679-415X, Toledo, v. 26, n.1, p.87-105, jan./jun. 2022. 


\section{INTRODUÇÃO}

O crescimento produtivo do setor agropecuário transformou o espaço rural brasileiro após a década de 1960, período de aceleração do processo de modernização e de tecnificação (BACHA, 2012). Nesta fase, a agropecuária foi beneficiada por várias políticas que favoreceram sua expansão. Uma das principais foi a do crédito rural, instituído pela Lei ${ }^{0} 4.829 / 1965$, a qual criou o Sistema Nacional de Crédito Rural (SNCR) com a finalidade de financiar as atividades agrícolas e pecuárias no Brasil (ROCHA; OZAKI, 2020).

Os objetivos do crédito rural estão descritos no Art. 3, da Lei $n^{0} 4.829 / 1965$, os quais buscam estimular os investimentos para armazenamento, beneficiamento e industrialização dos produtos agropecuários; favorecer o custeio da produção e a comercialização; fortalecer economicamente os produtores rurais, principalmente os pequenos e médios; além de incentivar os métodos racionais de produção (BRASIL, 1965).

Dessa forma, o crédito rural tornou-se uma das principais políticas destinadas ao setor agropecuário. Porém, no decorrer das últimas seis décadas o Brasil passou por diferentes abordagens econômicas, como consequência, a concessão de crédito destinado ao setor passou por várias alterações. Até meados da década de 1970, a concessão de crédito era abundante e beneficiava o processo de modernização da agropecuária, entretanto, favoreceu algumas regiões e os produtos destinados à exportação (BELIK; PAULILLO, 2001; BACHA, 2012). No final dos anos 1970, o sistema de concessão de crédito passou por dificuldades, a crise fiscal do Estado proporcionou mudanças em sua atuação, como consequência, os subsídios foram retirados favorecendo a criação de mecanismos privados (não oficiais) de crédito, concedido por empresas fornecedoras de insumos, tradings, agroindústrias e exportadores (SILVA, 2012).

Neste contexto, as duas décadas seguintes foram marcadas pela redução da oferta do crédito rural, porém, também foi um período de importantes mudanças. Segundo Gasques, Bacchi e Bastos (2017) na década de 1990 ocorreu uma mudança que se mantém até os dias atuais, as equalizações sobre as taxas de juros e dos preços, a qual constitui-se como uma forma de alavancar os rescursos financeiros para o crédito rural, mas com uma atuação reduzida do governo. Além disso, como forma de fomentar os pequenos agricultores foi criado um importante mecanismo de apoio, o Progama Nacional de Fortalecimento da Agricultura Familiar (PRONAF), instuído em 1996 pelo Decreto Presidencial no 1.946 (BRASIL, 1996).

O crédito rural estruturou-se novamente como um importante mecanismo indutor de desenvolvimento para os municípios brasileiros, favorecendo a exploração das potencialidades produtivas e a geração de valor econômico para as localidades (GALEANO; SILVA; SOUZA, 2017). Portanto, essa relevante política destina recursos financeiros para as operações de crédito de vários benificiários ${ }^{2}$ ligados ao setor agropecuário, com a finalidade de financiar o custeio da safra, os investimentos em bens e serviços, além do apoio à comercialização ou industrialização de seus produtos agrícolas e pecuários (BANCO CENTRAL DO BRASIL, 2021a).

Diante do exposto, o objetivo deste trabalho é analisar a distribuição espacial do crédito rural em relação ao valor adicionado bruto pela agropecuária para os municípios do Paraná,

\footnotetext{
${ }^{2}$ Os beneficiários do Crédito Rural são: Produtor rural (pessoa física ou jurídica); Cooperativa de produção agropecuária; Associação de produtores rurais; Pessoa física ou jurídica da atividade de pesquisa agropecuária; Pessoa física ou jurídica produtora de mudas, sementes, sêmen para inseminação artificial e embriões; Prestador de serviço de mecanização, de medição de lavoura ou de serviço de inseminação artificial à agropecuária; Beneficiador; Agroindústria; Cerealista; Silvícola/indígena; Pescador; Aquicultor; Torrefadora/indústria de café solúvel; Exportador de café; Silvicultor; Extrativista; Quilombola rural (BACEN, 2021a).
}

Informe GEPEC, ISSN:1679-415X, Toledo, v. 26, n.1, p.87-105, jan./jun. 2022. 
através do Índice Regional do Crédito Rural (IRCR), para os anos de 2008, 2013 e 2018; e analisar a evolução da distribuição e as concentrações do crédito rural no período de análise. A partir dessas análises será possível verificar se existe correlação espacial do crédito rural em relação ao valor adicionado bruto da agropecuária entre os municípios paranaenses, para tanto, utilizar-se-á uma Análise Exploratória de Dados Espaciais (AEDE).

Em suma, este trabalho estuda as características espaciais que possam contribuir para o mapeamento da participação dos municípios do Paraná no crédito rural, comparando com sua participação no valor adicionado bruto agropecuário, o que possibilita identificar disparidades em sua distribuição, de modo que os resultados aferidos possam contribuir para fortalecer esta relevante política pública.

Isto posto, o presente estudo está estruturado em quatro seções, incluindo esta introdução (1). Nas seções seguintes apresentam-se a metodologia (2), posteriormente a análise de resultados (3) e, por fim, as considerações finais (4).

\section{2.- METODOLOGIA}

As subseções seguintes referem-se os procedimentos metodológicos utilizados para mensurar o Índice Regional de Crédito Rural (IRCR) e a Análise Exploratória de Dados Espaciais (AEDE).

\section{1 - ÍNDICE REGIONAL DE CRÉDITO RURAL}

O instrumental metodológico do Índice Regional de Crédito (IRC), utilizado para medir a desigualdade na distribuição do crédito em um país, tem como referência o trabalho desenvolvido por Crocco et al. (2011). O IRC é uma adaptação do “Quociente Locacional”, um dos principais indicadores utilizados na análise regional, o qual objetiva identificar o comportamento locacional das atividades, apresentando a existência ou não de especialização nas diferentes regiões em comparação a região de referência.

Galeano, Silva e Souza (2017, p. 57) explicam que o IRC "compara a participação de uma região no total de crédito concedido no país com sua participação no PIB nacional”. Nesse contexto, a partir da formulação do IRC, Favaretto et al. (2020) estruturaram o Índice Regional de Crédito Rural (IRCR) e analisaram a distribuição do crédito rural para as microrregiões do Rio Grande do Sul entre 2000 a 2015. Nesse sentido, o IRCR objetiva comparar a participação do município em relação ao total de crédito rural concedido ao Estado com sua participação no Valor Adicionado Bruto da Agropecuária (VAB).

Portanto, como o objetivo deste trabalho é analisar a distribuição do crédito rural em relação ao valor adicionado bruto da agropecuária, para os municípios do Paraná nos anos 2008, 2013 e 2018, adaptou-se a metodologia utilizada por Favaretto et al. (2020) para calcular por municípios paranaenses. A fórmula é apresentada na sequência (Equação 1):

Em que:

$$
I R C R i=\frac{C R E D i / C R E D p r}{V A B i / V A B p r}
$$

$I R C R i=$ Índice Regional de Crédito Rural do município $i$;

$C R E D i=$ Crédito rural para o município $i$;

$C R E D p r=$ Crédito rural para o Paraná;

$V A B i=$ Valor adicionado bruto da agropecuária do município $i$;

$V A B p r=$ Valor adicionado bruto da agropecuária do Paraná.

Informe GEPEC, ISSN:1679-415X, Toledo, v. 26, n.1, p.87-105, jan./jun. 2022. 
Para analisar os resultados observa-se quando o IRCR for igual à unidade (IRCR=1), a participação de crédito concedido ao município é igual a sua participação do VAB agropecuário por ele gerado. E quando o IRCR for maior que a unidade (IRCR $>1$ ), o município tem uma participação maior na concessão do crédito rural do que sua participação no VAB agropecuário, neste sentido, quando a participação for menor que a unidade (IRCR $<1$ ), o município tem uma menor participação na concessão de crédito rural do que sua participação no VAB agropecuário. Do mesmo modo, aplicou-se o mesmo cálculo para o Estado do Paraná em relação ao Brasil, o qual foi realizado anualmente de 2008 a 2018, e, para os municípios, foi calculado a cada cinco anos.

Os dados utilizados referente ao valor total do crédito rural, no qual estão incluídos os investimentos de custeio, investimento, comercialização e apoio a industrialização, estão disponíveis no Anuário Estatístico (até 2012) e na Matriz de Dados do Crédito Rural (até 2018), coletados no site do Banco Central do Brasil - BACEN (2021b, 2021c). O Valor Adicionado Bruto da Agropecuária ${ }^{3}$ (VAB) dos 399 municípios do Paraná e para o Brasil foram extraídos do Instituto Brasileiro de Geografia e Estatística - IBGE (2021a). Os dados são disponibilizados anualmente, 2008 a 2018, os quais foram deflacionados pelo IGP-DI anual, disponível no Instituto de Pesquisa Econômica Aplicada - IPEA (2021). Por fim, o período de análise, 2008 a 2018, foi definido conforme a disponibilidade dos dados do VAB da Agropecuária.

Figura 1 - Municípios e Mesorregiões do Estado do Paraná

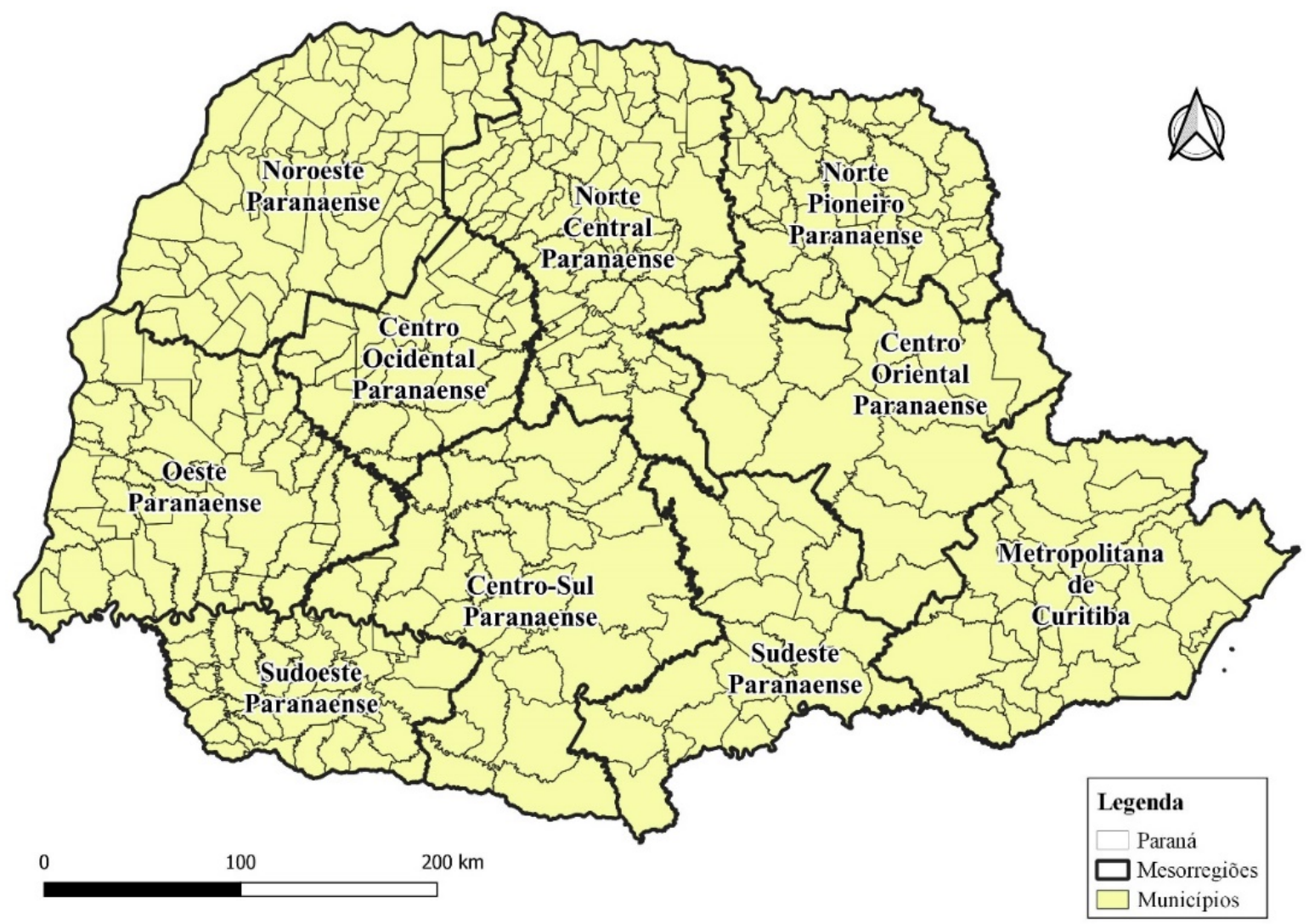

Fonte: Dados da pesquisa.

3 O Valor Adicionado Bruto da Agropecuária divulgado pelo IBGE possuem caráter anual, porém até a data de estruturação deste estudo o último período divulgado foi para o ano de 2018.

Informe GEPEC, ISSN:1679-415X, Toledo, v. 26, n.1, p.87-105, jan./jun. 2022. 
O Paraná está dividido em 399 municípios (Figura 1), segundo o Instituto Brasileiro de Geografia e Estatística - IBGE (2021b). Optou-se analisar por municípios, com o intuito de identificar as disparidades na concessão do crédito rural e no valor adicionado bruto da agropecuária entre os mesmos.

\section{2 - ANÁLISE EXPLORATÓRIA DE DADOS ESPACIAIS (AEDE)}

A Análise Exploratória de Dados Espaciais (AEDE) objetiva identificar se aos municípios que recebem maiores valores de crédito em custeio, investimento, comercialização e apoio a industrialização estão correlacionados espacialmente com municípios que possuem, em média, um alto Valor Adicionado Bruto agropecuário. Para isso, analisou-se temporalmente se o crédito rural está espacialmente correlacionado com o VAB agropecuário.

O instrumental metodológico da AEDE é a somatória de várias técnicas que auxiliam a análise estatística dos dados distribuídos no espaço. Essas técnicas permitem verificar padrões de associação espacial (clusters) e identificar regiões atípicas (outliers espaciais), além de outras situações de divergências espaciais na distribuição dos dados na região de estudo, em âmbito global e local. O estudo da AEDE inicia-se com o teste da hipótese de que as informações sejam distribuídas aleatoriamente. Essa aleatoriedade espacial das variáveis em análise da região mostra se os dados possuem ou não correlação com regiões vizinhas. Dessa forma, as informações autocorrelacionadas são ordenadas seguindo uma sequência espacial. Esses resultados são apresentados em um mapa, o qual fornece os atributos da variável e possibilita a visualização dos arranjos desses atributos no espaço (ALMEIDA, 2012).

Para testar a existência de correlação espacial foi utilizado o $I$ de Moran bivariado (Equação 2), conforme Almeida (2012, p. 118):

$$
I^{z_{1} z_{2}}=\frac{n}{S_{0}} \frac{z_{1}^{\prime} W z_{2}}{z_{1}^{\prime} z_{1}}
$$

Se a matriz $W$ for normalizado na linha, a equação é expressa como (Equação 3):

$$
I=\frac{z^{\prime} W z_{2}}{z_{1}^{\prime} z_{1}}
$$

Em que $z_{1}$ é uma variável de interesse (Crédito rural), $z_{2}$ são os valores da outra variável de interesse na região vizinha (VAB), $W$ é a matriz de ponderação espacial. Almeida (2012, p. 118) ressalta que este coeficiente possui duas variáveis distintas, assim, "o numerador referese a uma medida de covariância do tipo ponto cruzado, ao passo que o denominador diz respeito a um reescalonamento, usando a variância dos dados”.

No diagrama de dispersão do $I$ de Moran bivariado plotado no eixo das abcissas estão os valores do Valor Adicionado Bruto da agropecuária (VAB) $\left(z_{2}\right)$, observados nos 399 municípios paranaenses, com os valores do crédito rural (Cred_total) $\left(z_{1}\right)$, observados entre os municípios vizinhos, no eixo das ordenadas (Figura 2). O gráfico de dispersão da nuvem de pontos mostra os valores das duas variáveis analisadas, esse indica a declividade da reta de regressão. Para alcançar essa declividade se faz necessário uma regressão linear simples pelos Mínimos Quadrados Ordinários (MQO), expressa segundo Almeida (2012) (Equação 4):

$$
W_{z_{2}}=\propto+\beta_{z_{1}}+\varepsilon
$$

Em que $\alpha$ é a constante, $\beta$ é o coeficiente angular e $\varepsilon$ o erro aleatório.

O coeficiente do I de Moran bivariado pode ser estimado pelo MQO (Equação 5):

$$
\hat{\beta}=I^{z_{1} z_{2}}=\frac{z_{1} W z_{2}}{z_{1}^{\prime} z_{1}}
$$

Informe GEPEC, ISSN:1679-415X, Toledo, v. 26, n.1, p.87-105, jan./jun. 2022. 
Em que $W z_{2}$ é o coeficiente angular da reta de regressão da defasagem espacial contra a variável de interesse $z_{1}$.

Para compreensão do diagrama de Moran bivariado (Figura 2) apresentam-se quatro quadrantes. O primeiro quadrante, exibe o agrupamento dos valores Alto-Alto (AA), nesse quadrante apresentam-se os municípios com valores altos do $\mathrm{VAB}$, circundados de municípios com valores também altos da outra variável, o crédito rural. No segundo quadrante, mostra o agrupamento dos valores Baixo-Alto (BA), ou seja, é o agrupamento dos municípios com os valores baixos do $\mathrm{VAB}$, circundados pelos municípios com os valores altos do crédito rural. $\mathrm{O}$ terceiro quadrante é o agrupamento dos valores Baixo-Baixo (BB), que apresentam os municípios com valores baixos do VAB que são vizinhos de municípios com valores baixos do crédito rural. Por fim, o quarto quadrante encontra-se o agrupamento dos valores Alto-Baixo (AB), ou seja, o agrupamento dos municípios que exibem os valores alto do VAB, circundados de municípios com baixos valores do crédito rural.

Figura 2 - Exemplo do diagrama de dispersão de Moran Bivariado para Crédito Rural e o VAB nos 399 municípios do Paraná

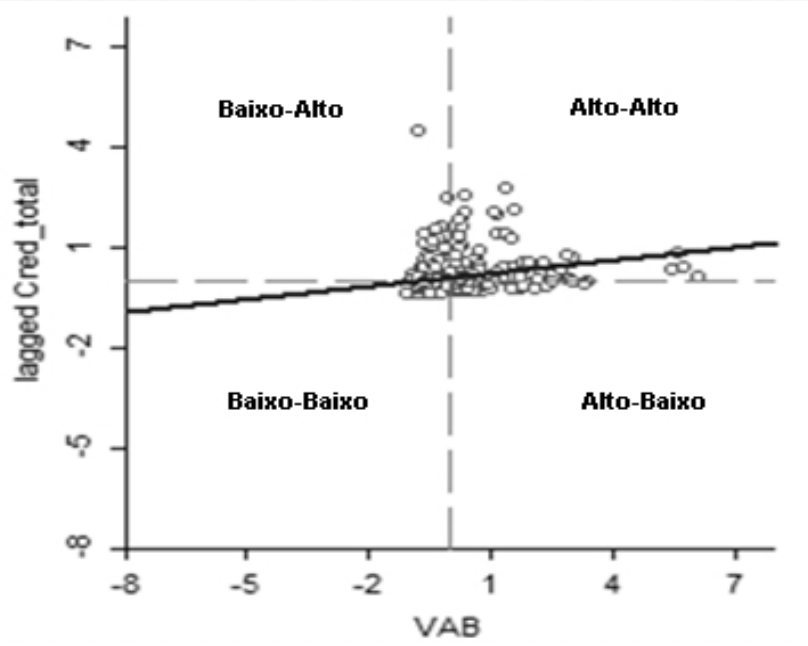

Fonte: Elaboração própria com base em Almeida (2012).

Após aferir o coeficiente de autocorrelação espacial global bivariado é possível aferir a medida de autocorrelação espacial local multivariada. Ao analisar duas variáveis de interesse (VAB e o crédito rural), $x_{i}$ e $y_{i}$, respectivamente, e ao padronizá-las, obtém-se, $z_{1 i}$ e $z_{2 i}$. A equação do $I$ de Moran local bivariado é a seguinte (Equação 6) (ALMEIDA, 2012, p. 132):

$$
I_{i}^{z_{1} z_{2}}=z_{1 i} W z_{2 i}
$$

Em que $z_{1 i}$ é a variável de interesse e $W z_{2 i}$ é a defasagem espacial padronizada $z_{2 i}$. Assim, apenas os vizinhos da observação $i$ fazem parte do cálculo, definidos por uma matriz de pesos espaciais (ALMEIDA, 2012). Se os resultados da autocorrelação espacial local multivariada forem significativos, podem ser apresentados em um mapa de significância bivariada do Moran local, esse mapa mostra os padrões de associação espacial entre as regiões de estudo.

\section{3 - ANÁLISE DOS RESULTADOS}

Nesta seção apresentam-se os resultados da distribuição espacial do crédito rural em relação ao valor adicionado bruto da agropecuária para o Paraná e seus municípios, a partir do índice Regional de Crédito rural, para o período de 2008 a 2018 (Paraná) e, para os anos 2008, 2013 e 2018 (Municípios). Ainda, apresentam-se os resultados se há autocorrelação e

Informe GEPEC, ISSN:1679-415X, Toledo, v. 26, n.1, p.87-105, jan./jun. 2022. 
heterogeneidade espacial do crédito rural e valor adicionado bruto da agropecuária entre os municípios, por meio da Análise Exploratória de Dados Espaciais (AEDE).

\section{1 - ÍNDICE REGIONAL DE CRÉDITO RURAL PARA O PARANÁ}

O crédito rural constitui-se como um mecanismo essencial da política agrícola, pois fornece recursos financeiros ao setor agropecuário à juros diferenciados do mercado de crédito com o objetivo fomentar os investimentos, apoiar o custeio da produção e a comercialização dos produtos gerados pelo setor. Além disso, proporciona a geração de renda, estimula a agricultura familiar e incentiva o uso de práticas sustentáveis e novas tecnologias (MINISTÉRIO DA AGRICULTURA, PECUÁRIA E ABASTECIMENTO, 2021).

O Gráfico 1 apresenta a evolução do volume de crédito rural que foi contratado pelo setor agropecuário no Brasil, entre os anos de 2008 a 2018. Ressalta-se que o volume de recursos financeiros aumentou continuamente entre 2008 a 2014, reduzindo em 2015 e 2016, esses números podem ser justificados pelo período de recessão econômica no Brasil. No entanto, nota-se recuperação nos anos de 2017 e 2018. No período total, o crédito rural brasileiro apresentou uma taxa geométrica média anual de crescimento de 4,71\% a.a.. O Paraná acompanhou o movimento apresentado pelo Brasil, sua taxa geométrica média anual de crescimento foi de $4,95 \%$ a.a..

Gráfico 1 - Crédito rural, Paraná e Brasil, R\$ bilhões - 2008/2018

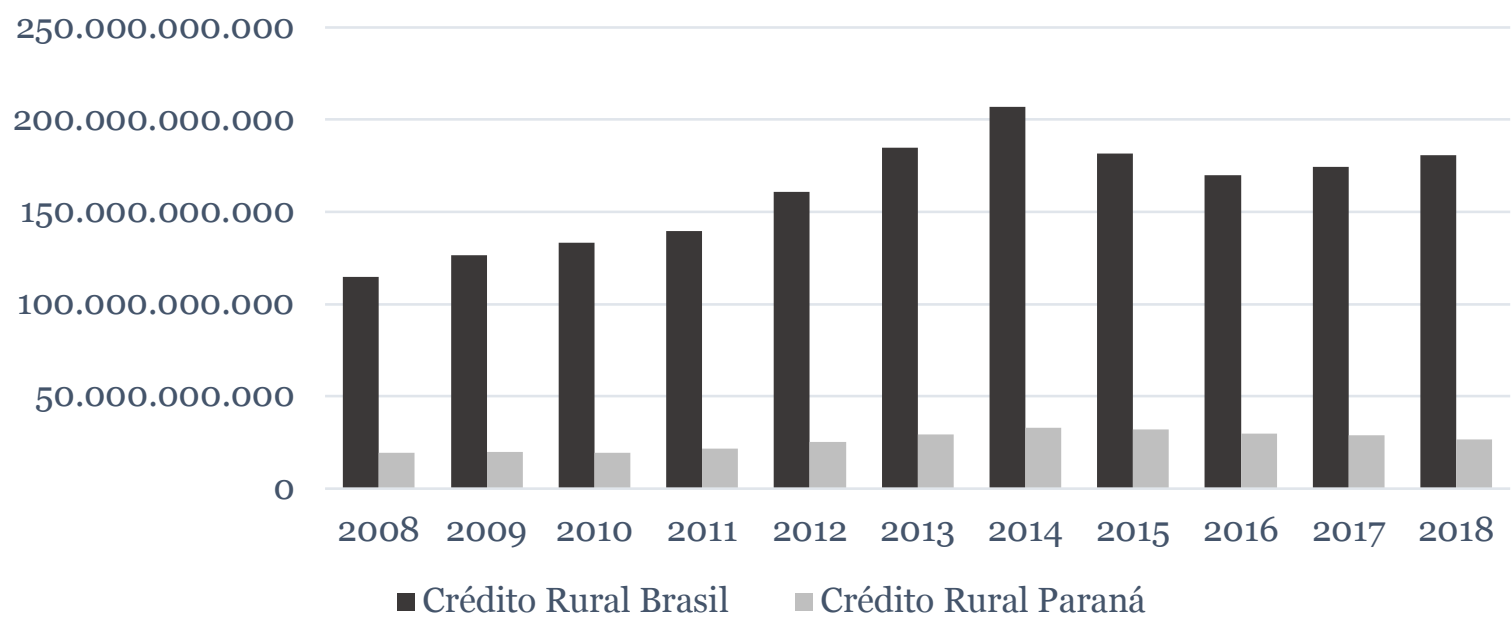

Fonte: Elaboração própria com base nos dados do Banco Central do Brasil - BACEN (2021b, 2021c), deflacionados pelo IGP-DI 2018=100 (Instituto de Pesquisa Econômica Aplicada).

O Valor Adicionado Bruto da agropecuária brasileira e paranaense estão apresentados no Gráfico 2. No período de 2008 a 2018, o VAB do Brasil aferiu uma taxa geométrica média anual de crescimento de $2,78 \%$ a.a.. No Paraná, o VAB apresentou taxa geométrica média anual de crescimento superior a do país, em 3,54\% a.a.. Destaca-se que a agropecuária paranaense teve uma participação média de $11,29 \%$, no período. Na composição do VAB agropecuário do Paraná a agricultura participa com $71,6 \%$, a pecuária com $22,4 \%$ e a silvicultura, pesca e aquicultura com 6\%, dados para 2018 (IPARDES, 2021). 
Gráfico 2 - Valor Adicionado Bruto da Agropecuária, Paraná e Brasil, R \$ bilhões - 2008-2018

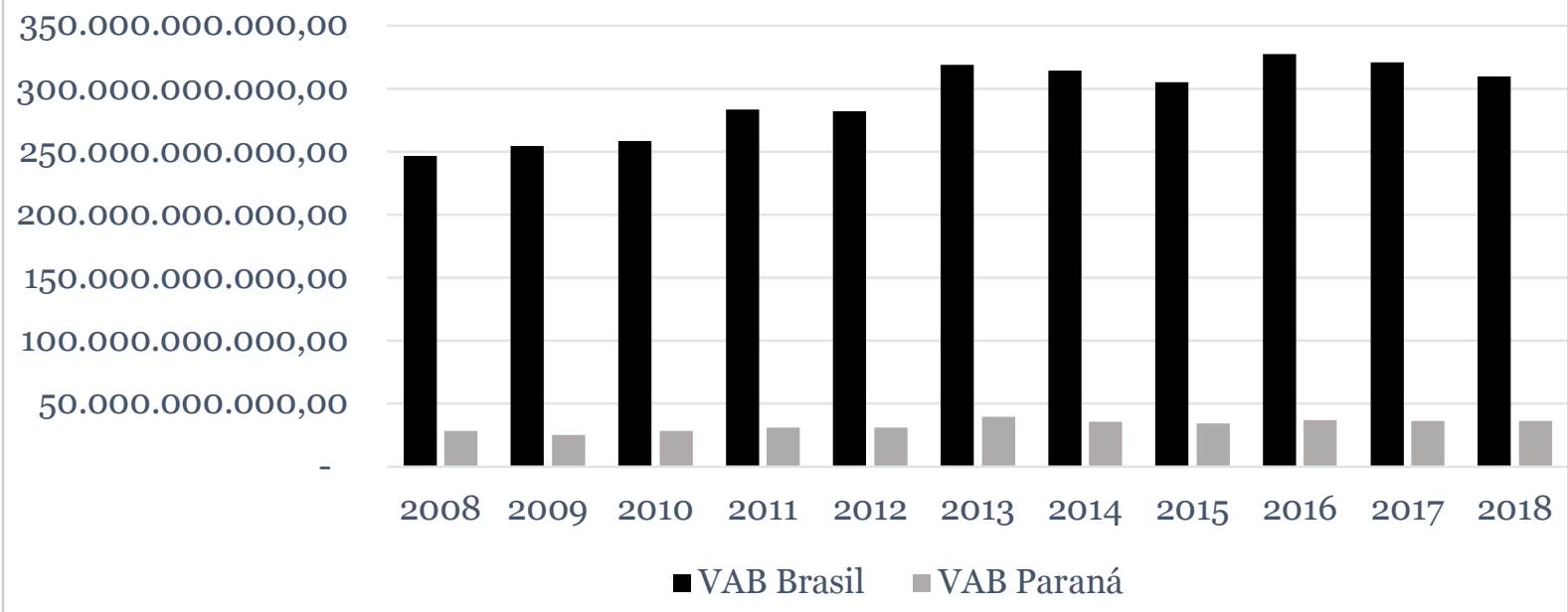

Fonte: Elaboração própria, com base nos dados do Instituto Brasileiro de Geografia e Estatística - IBGE (2021a), deflacionados pelo IGP-DI 2018=100 (Instituto de Pesquisa Econômica Aplicada).

Ao considerar o crédito rural em relação ao valor adicionado, aferiu-se a distribuição do crédito rural, analisada por meio do Índice Regional de Crédito rural (IRCR), para o Paraná, no período de 2008 a 2018 (Gráfico 3).

Gráfico 3 - Índice Regional de Crédito Rural do Paraná - 2008-2018

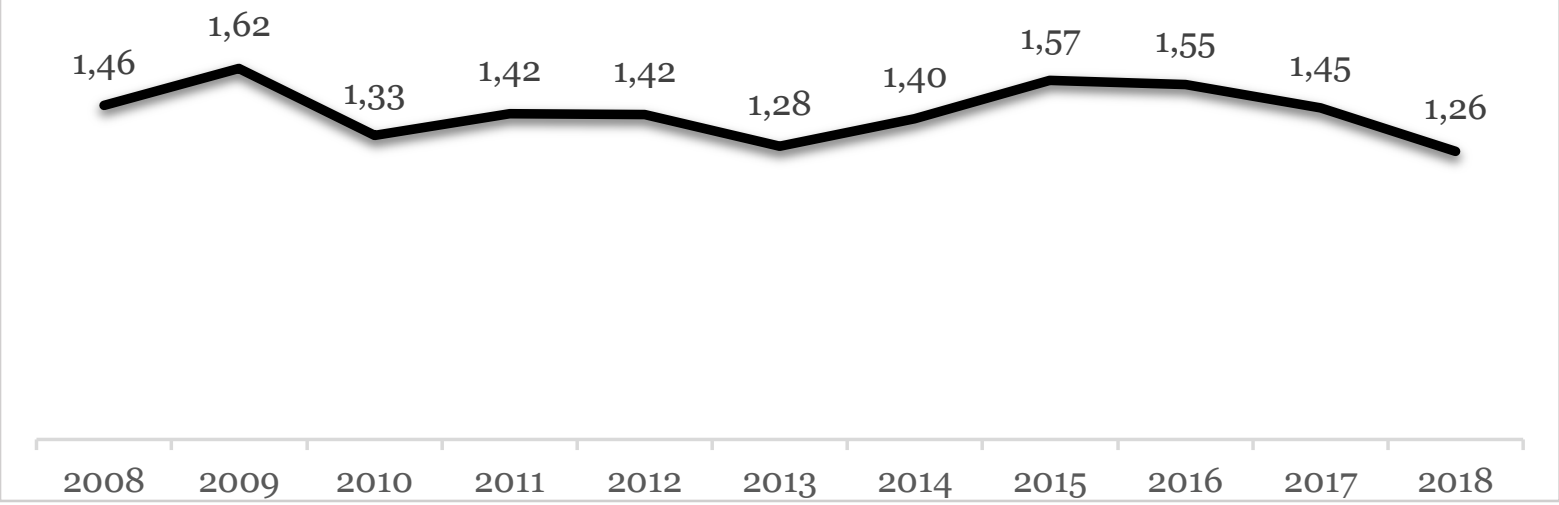

Fonte: Elaboração própria com base nos dados do Banco Central do Brasil (2021b, 2021c) e do Instituto Brasileiro de Geografia e Estatística (2021a).

O resultado mostrou que o estado apresentou um índice maior que a unidade durante todo o período, confirmando que sua participação no total de crédito rural manteve-se acima de sua participação no total do valor adicionado bruto da agropecuária. O IRCR variou entre 1,62 e 1,26, os quais correspondem aos máximos e mínimos, com o máximo de 1,62, aferido no ano de 2009 e, o menor IRCR de 1,26, no ano de 2018.

O Índice Regional de Crédito Rural (IRCR) para o Paraná apresentou oscilação acompanhado de uma tendência de baixa. Convém destacar que a produção agropecuária está mais suscetível a situações climáticas adversas que impactam o futuro da produção. Tal fato contribui para explicar a oscilação do VAB agropecuário, pois nos anos de 2009 e 2014 ocorreram fortes estiagens no Paraná, impactando negativamente a produção agrícola, situação que torna explicável o aumento do IRCR nesses dois períodos. 


\section{2 - DISTRIBUIÇÃO ESPACIAL DO ÍNDICE REGIONAL DE CRÉDITO RURAL (IRCR) NO PARANÁ}

A Figura 3 apresenta a participação percentual do valor adicionado bruto da agropecuária entre os municípios paranaenses. Nota-se que, apenas 5 municípios possuem participação no VAB agropecuário acima de 1\%, em 2008, esses foram: Castro (1,62\%), Tibagi (1,56\%), Toledo (1,51\%), Cascavel (1,49\%) e Guarapuava (1,05\%). Já os municípios com as menores participações percentuais somam 360, apresentam-se os dez com as menores participações: Matinhos (o,002\%), Pinhais (o,003\%), Pontal do Paraná (o,003\%), Quatro Barras (0,02\%), Paranaguá (0,02\%), Curitiba (0,03\%), Miraselva (0,03\%), Antonina (0,03\%), Porto Rico (0,03\%), Itaúna do Sul (0,04\%).

Figura 3 - Participação \% dos municípios do Paraná no Valor Adicionado Bruto da Agropecuária $2008 / 2018$

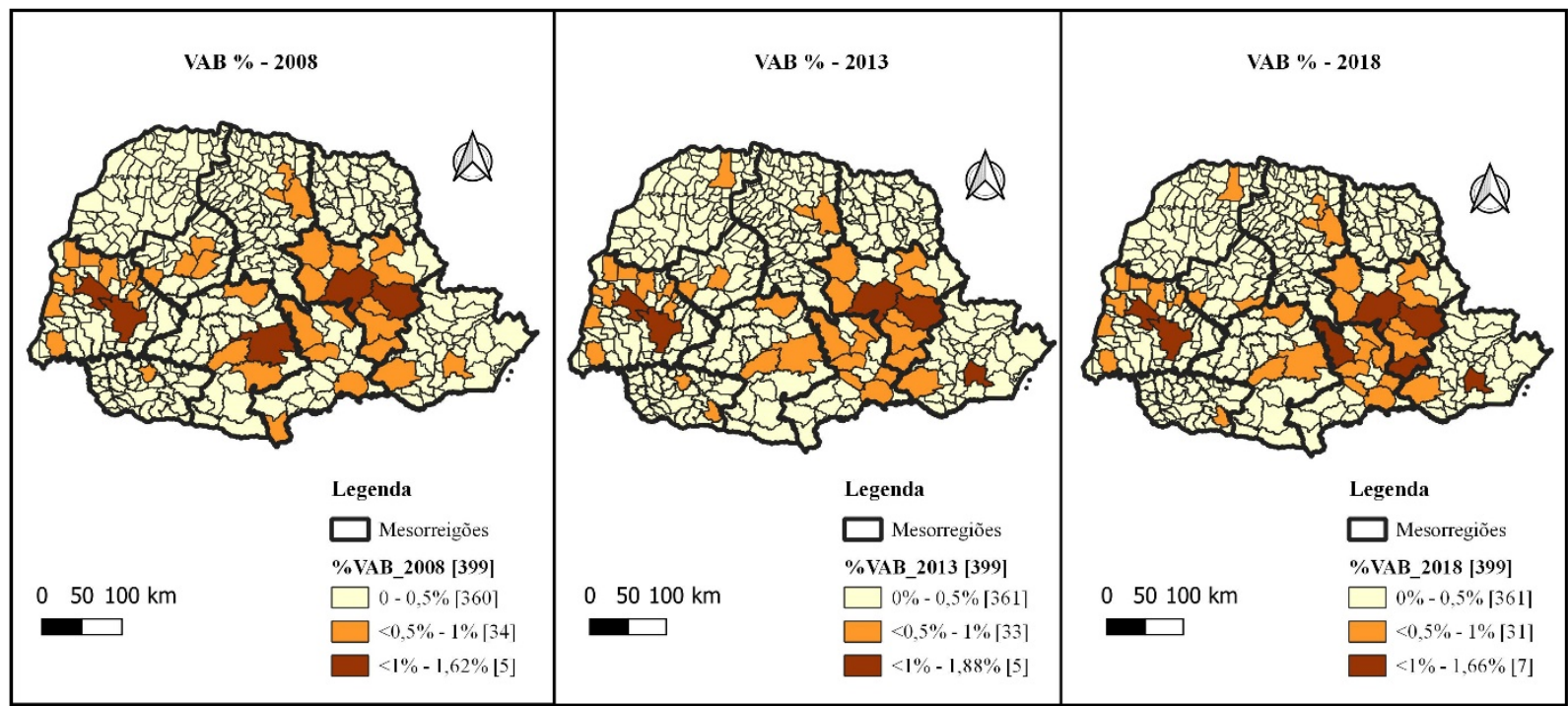

Fonte: Elaboração própria com base nos dados do IBGE (2021a), deflacionados pelo IGP-DI 2018=100 (Instituto de Pesquisa Econômica Aplicada).

No ano de 2013, os municípios paranaenses com participação superior a 1\% no VAB agropecuário foram somente 5: Castro (1,88\%), Cascavel (1,76\%), Tibagi (1,55\%), Toledo (1,32\%) e São José dos Pinhais (1,29\%). Os municípios com menores participações no VAB agropecuário somaram 361, apresentam-se os dez com as menores participações: Matinhos (0,002\%), Pinhais (0,003\%), Pontal do Paraná (0,005\%), Quatro Barras (0,01\%), Paranaguá (o,02\%), Miraselva (o,03\%), São Manoel do Paraná (o,03\%), Flórida (o,03\%), Curitiba (o,03\%), Itaúna do Sul (0,04\%).

No ano de 2018, 7 municípios com maiores participações no VAB agropecuário, os quais são: Cascavel (1,66\%), Castro (1,52\%), Toledo (1,36\%), São José dos Pinhais $(1,30 \%)$, Tibagi (1,26\%), Palmeira (1,15\%) e Prudentópolis (1,02\%). E os municípios com menores participações no VAB agropecuário somaram 361, apresentam-se os dez com as menores participações: Pinhais (0,003\%), Matinhos (0,004\%), Pontal do Paraná (0,01\%), Quatro Barras (0,01\%), Miraselva (0,03\%), Paranaguá (0,03\%), Curitiba (0,03\%), Antonina (0,04\%) Porto Rico (0,04\%) Itaúna do Sul (0,04\%).

Já, quando analisada a distribuição espacial do Paraná para o crédito rural (Figura 4), percebe-se que em 2008, 14 municípios apresentaram participação superior a 1\%, os quais são: Campo Mourão (8,81\%), Londrina (4,69\%), Cascavel (4,39\%), Palotina (3,06\%), Guarapuava

Informe GEPEC, ISSN:1679-415X, Toledo, v. 26, n.1, p.87-105, jan./jun. 2022. 
(2,46\%), Medianeira (2,38\%), Toledo (1,90\%), Castro (1,84\%), Rolândia (1,83\%), Maringá (1,80\%), Cafelândia (1,31\%), Marechal Cândido Rondon (1,14\%), Carambeí (1,10\%) e Assis Chateaubriand (1,01\%). Os municípios com as menores participações percentuais no crédito rural somaram 360, apresentam-se os dez com a menor participação: Pontal do Paraná (o,000\%), Matinhos (0,000\%), Tunas do Paraná (o,001\%), Quatro Barras (0,001\%), Campina Grande do Sul (0,002\%), Antonina (0,003\%), Piraquara (0,005\%), Fazenda Rio Grande (o,01\%), Guaraqueçaba (o,01\%), Rio Branco do Sul (0,01\%).

Figura 4 - Participação \% dos municípios do Paraná no Crédito Rural - 2008/2018

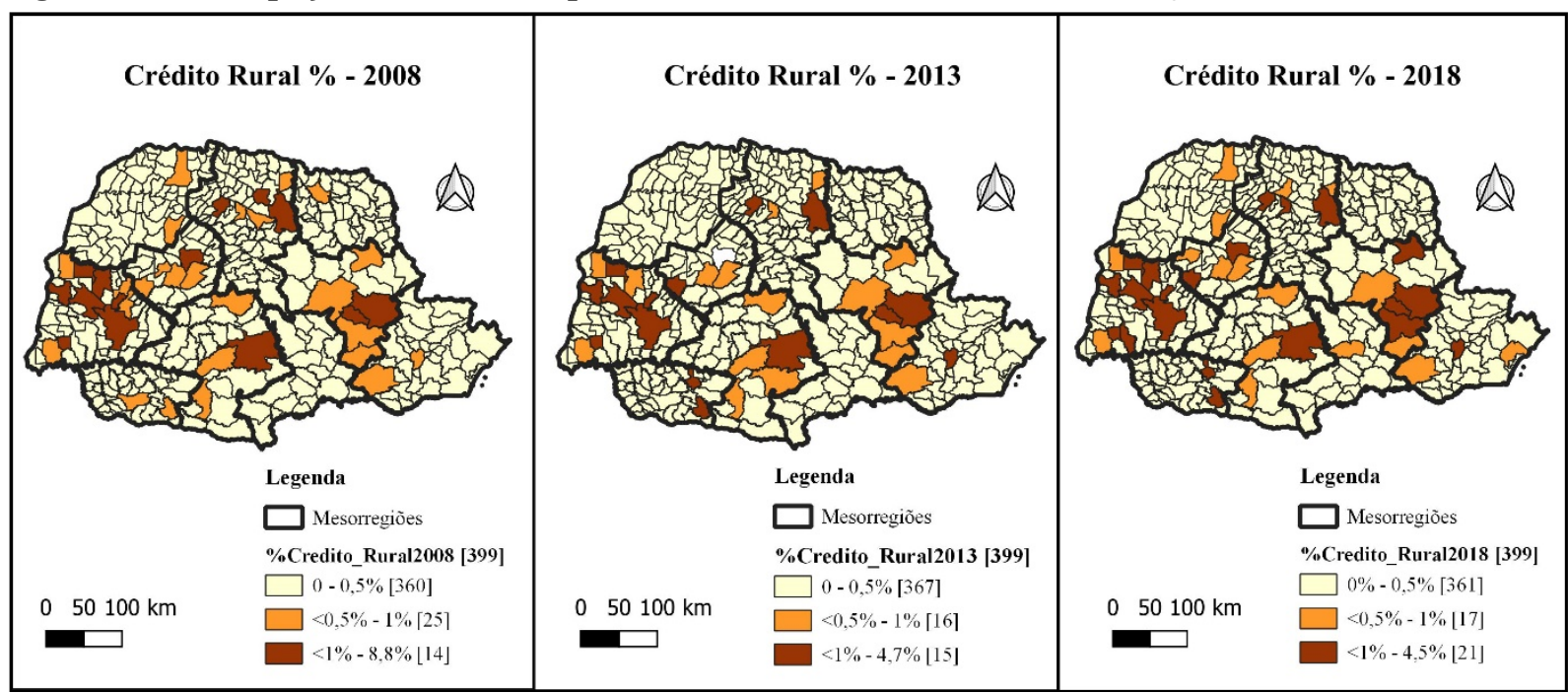

Fonte: Elaboração própria com base nos dados do Banco Central do Brasil - BACEN (2021b, 2021c), deflacionados pelo IGP-DI 2018=100 (Instituto de Pesquisa Econômica Aplicada).

Em 2013, 15 municípios apresentaram participações acima de 1\% no crédito rural: Campo Mourão (6,17\%), Palotina (3,75\%), Maringá (3,73\%), Londrina (3,66\%), Cascavel (2,97\%), Medianeira (2,85\%), Guarapuava (2,83\%), Curitiba (2,53\%), Cafelândia $(2,48 \%)$, Castro (2,13\%), Carambeí (1,45\%), Toledo (1,39\%), Ubiratã (1,33\%), São João (1,19\%), Marechal Cândido Rondon (1,14\%) e Pato Branco (1,01\%). Já os municípios com menores participações no crédito rural somaram 367, apresentam-se os dez com a menor participação: Quatro Barras (0,000\%), Pontal do Paraná (0,000\%), Matinhos (0,000\%), Tunas do Paraná (o,002\%), Antonina (0,003\%), Campina Grande do Sul (o,003\%), Piraquara (0,004\%), Fazenda Rio Grande (0,004\%), Telêmaco Borba (0,005\%), Paranapoema (0,01\%).

Em 2018, foram 21 municípios que apresentaram participações acima de 1\% no crédito rural: Maringá (4,54\%), Castro (3,89\%), Londrina (3,29\%), Palotina (3,19\%), Curitiba (3,18\%), Cascavel (2,90\%), Medianeira (2,76\%), Campo Mourão (2,74\%), Cafelândia (2,49\%), Guarapuava (2,09\%), Toledo (1,73\%), Ponta Grossa (1,55\%), Pato Branco (1,52\%), São João (1,44\%), Ubiratã $(1,41 \%)$, Carambeí (1,35\%), Marechal Cândido Rondon (1,31\%), Arapoti (1,16\%), Matelândia (1,15\%), Assis Chateaubriand (1,09\%), e Mandaguari (1,03\%). Os municípios com menores participações no crédito rural somaram 361, apresentam-se os dez com as menores participações: Quatro Barras (0,000\%), Pontal do Paraná (0,000\%), Matinhos (o,000\%), Tunas do Paraná (0,001\%), Campina Grande do Sul (o,001\%), Antonina (0,001\%), Fazenda Rio Grande (o,002\%), Miraselva (o,004\%), Piraquara (0,004\%), Inácio Martins (0,01\%).

Analisando a Figura 3, é possível verificar que a variável VAB, apresenta distribuição espacial semelhante em todo o período de análise, com maiores concentrações entre os municípios da mesorregião Oeste, Centro-Sul e Centro-Oriental. A variável crédito rural,

Informe GEPEC, ISSN:1679-415X, Toledo, v. 26, n.1, p.87-105, jan./jun. 2022. 
Figura 4, mostra similaridade com o VAB, contudo, além das regiões mencionadas, a distribuição do crédito rural foi crescente nos municípios da região Norte-Central e o CentroOcidental do Paraná. Destaca-se que as maiores participações no crédito rural e no valor adicionado bruto da agropecuária ocorrem entre os municípios caracterizados pela diversificação das atividades agropecuárias, impulsionadas por empresas e cooperativas agroindustriais. No entanto, os municípios com as menores participações nessas variáveis fazem parte da região metropolitana de Curitiba e da região litorânea, regiões que não possuem a agropecuária como atividade principal, porém são regiões importantes para o escoamento da produção até o Porto de Paranaguá.

Cabe ressaltar também, que do total do crédito rural concedido ao Paraná em 2008, $86,8 \%$ foram destinados as atividades agrícolas e $13,2 \%$ foram recursos para a pecuária. No ano de 2013, essa proporção foi semelhante, $78,4 \%$ destinou-se a agricultura e $21,6 \%$ para a pecuária. Em 2018, a concessão de crédito para a agricultura foi de $72,6 \%$ e a pecuária $27,4 \%$, evidenciando a ampliação do crédito pecuário. Tal fato, pode ser justificado pelos investimentos em novas tecnologias utilizadas na pecuária paranaense que aumentaram sua produtividade (CAPUCHO; PARRÉ, 2012).

A Figura 5 apresenta a distribuição espacial do Índice Regional de Crédito Rural (IRCR) para os municípios paranaenses, para os anos de 2008, 2013 e 2018. Observa-se que os 399 municípios paranaenses apresentaram simetrias e diferenças regionais, fato que contribui para descrever que a distribuição do crédito rural entre os munícipios não acompanha sua participação no valor adicionado bruto da agropecuária.

Figura 5 - Índice Regional de Crédito Rural - IRCR - 2008/2018

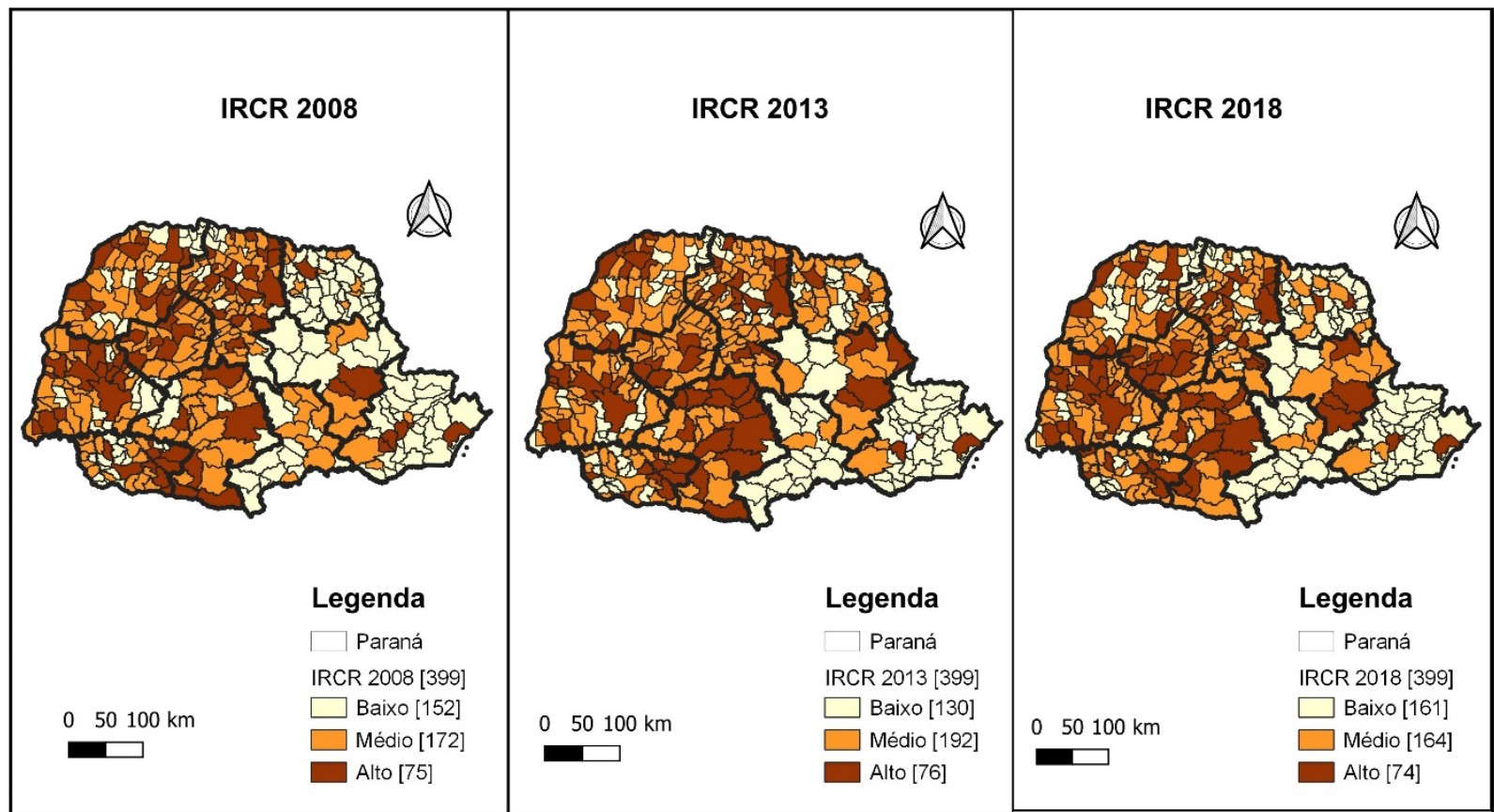

Fonte: Resultados da pesquisa.

*Nota: IRCR Baixo = entre o e 0,50; IRCR Médio = entre <0,50 e 1,0; IRCR Alto = acima de 1,0.

Nota-se que, em 2008, 75 municípios aferiram o IRCR superior a unidade (IRCR = $<1,0), 172$ munícipios apresentaram o IRCR médio (<0,50 e 1,o), e, em 152 municípios o IRCR foi baixo (resultados entre o e 0,5). Já em 2013, foram 77 municípios com o IRCR alto, na classificação médio foram 192 e 130 aferiram resultados classificados como baixo. Por fim, em 2018, 74 municípios possuíam um IRCR alto, 164 médio e 161 baixo.

Informe GEPEC, ISSN:1679-415X, Toledo, v. 26, n.1, p.87-105, jan./jun. 2022. 
Os municípios com os maiores IRCR (IRCR $=<2,0$ ) em 2008 foram: Curitiba (35,5), Pinhais (25,5), Campo Mourão (16,3), Medianeira (7,5), Maringá $(5,6)$, Londrina $(5,19)$, Nova Laranjeiras (4,70), Pontal do Paraná (4,25), Palmital (4,09), Rio Negro (3,94), Cascavel $(2,95)$, Cafelândia $(2,68)$, Guarapuava $(2,45)$, Paranapoema $(2,18)$, Boa Esperança $(2,12)$, Lobato $(2,05)$, Sertaneja $(2,02)$. Os municípios com os menores IRCR foram identificados nas Mesorregiões Norte-Pioneiro, Centro-Oriental, Sudeste e Metropolitana de Curitiba.

No ano de 2013, os municípios que apresentaram IRCR<2,o foram: Curitiba $(73,12)$, Maringá (12,53), Campo Mourão (12,52), Paranaguá (12,49), Pinhais (10,44), Medianeira $(8,21)$, Cafelândia $(5,23)$, Palotina $(4,64)$, Nova Londrina $(4,53)$, Londrina $(3,98)$, São João $(3,71)$, Santo Inácio $(3,53)$, Mandaguari $(3,51)$, Guarapuava $(3,09)$ e Ubiratã $(2,17)$. Os menores IRCR para 2013, apresentam-se em maioria nas mesorregiões Sudeste, Centro-Oriental e Metropolitana de Curitiba.

Em 2018, Curitiba (90,71), Paranaguá (17,54), Maringá (16,05), Medianeira $(8,87)$, Cafelândia (6,51), Campo Mourão (6,01), Pinhais (5,68), São João (4,58), Palotina $(4,35)$, Londrina (3,79), Matelândia (3,30), Ibiporã $(2,68)$, Castro $(2,56)$, Ubiratã $(2,49)$, Pato Branco $(2,39)$, Paraíso do Norte $(2,35)$, Mandaguari $(2,25)$, Guarapuava $(2,16)$ e Marechal Cândido Rondon $(2,14)$. Já os menores IRCR encontram-se nos municípios do Sudeste, CentroOriental, Norte-Pioneiro, Metropolitana de Curitiba e Noroeste.

\section{3 - RESULTADOS DA ANÁLISE EXPLORATÓRIA DE DADOS ESPACIAIS (AEDE)}

Nesta parte do estudo verifica-se a autocorrelação espacial do crédito rural em relação ao valor adicionado bruto da agropecuária entre os municípios paranaenses. Para isso, foi utilizado a estatística do I de Moran Bivariado Global e Local. O I de Moran Bivariado Global mostra o nível de dependência espacial entre todos os municípios para as variáveis do crédito rural total e do VAB agropecuário. Se o valor for positivo, o I de Moran Bivariado Global aponta correlação espacial positiva entre as duas variáveis para cada ano. E o I de Moran Bivariado Local verifica a covariância entre um determinado município e seus vizinhos.

A primeira etapa da análise se encontra no Quadro 1, que exibe os resultados do I de Moran Bivariado Global entre as matrizes de pesos espaciais. A matriz de defasagem espacial com o melhor resultado foi a do tipo Torre de contiguidade 1, para todos os anos do estudo.

Quadro 1 - Matriz de pesos espaciais - 2008/2018

\begin{tabular}{|c|c|c|c|c|c|c|c|}
\hline Crédito Rural Total/VAB 2008 & Rainha & Torre & $2 \mathbf{k}$ & $4 k$ & $6 \mathbf{k}$ & $8 \mathbf{k}$ & $10 \mathbf{k}$ \\
\hline \multicolumn{8}{|l|}{$\underline{2008}$} \\
\hline I de Moran & 0.124 & $\underline{0.128}$ & 0.093 & 0.093 & 0.093 & 0.087 & 0.093 \\
\hline $\begin{array}{c}\text { Teste de significância (999 } \\
\text { permutações) }\end{array}$ & 0.002 & 0.002 & 0.018 & 0.003 & 0.001 & 0.001 & 0.001 \\
\hline \multicolumn{8}{|l|}{$\underline{2013}$} \\
\hline I de Moran & 0.118 & 0.121 & 0.107 & 0.095 & 0.112 & 0.094 & 0.097 \\
\hline $\begin{array}{c}\text { Teste de significância (999 } \\
\text { permutações) }\end{array}$ & 0.001 & 0.001 & 0.013 & 0.003 & 0.001 & 0.001 & 0.001 \\
\hline \multicolumn{8}{|l|}{$\underline{\mathbf{2 0 1 8}}$} \\
\hline I de Moran & 0.133 & o.136 & 0.124 & 0.108 & 0.123 & 0.103 & 0.108 \\
\hline $\begin{array}{c}\text { Teste de significância (999 } \\
\text { permutações) }\end{array}$ & 0.001 & 0.001 & 0.006 & 0.001 & 0.001 & 0.001 & 0.001 \\
\hline
\end{tabular}

Fonte: Elaboração própria. 
O I de Moran Bivariado para Torre é positivo e significativo em $2008(0,128), 2013$ $(0,121)$ e $2018(0,136)$. Isso indica uma correlação espacial global positiva entre crédito rural e o valor adicionado bruto, isto é, existe dependência espacial entre os municípios e no estado de modo geral. Dessa forma, pode-se afirmar que os municípios com elevada participação no crédito rural são vizinhos de municípios que apresentam também elevada participação no VAB.

Os pontos no diagrama (Figura 6) mostram a dependência entre os municípios e o Paraná, em 2008, 2013 e 2018. Com o diagrama de dispersão é possível classificar os municípios de acordo com os quatro regimes, os quais são Alto-Alto (AA), Baixo-Baixo (BB), Alto-Baixo (AB) e Baixo-Alto (BA).

Figura 6 - Diagrama de dispersão do $I$ de Moran bivariado do tipo Torre para o Crédito Rural/Valor Adicionado Bruto Agropecuário - 2008/2018

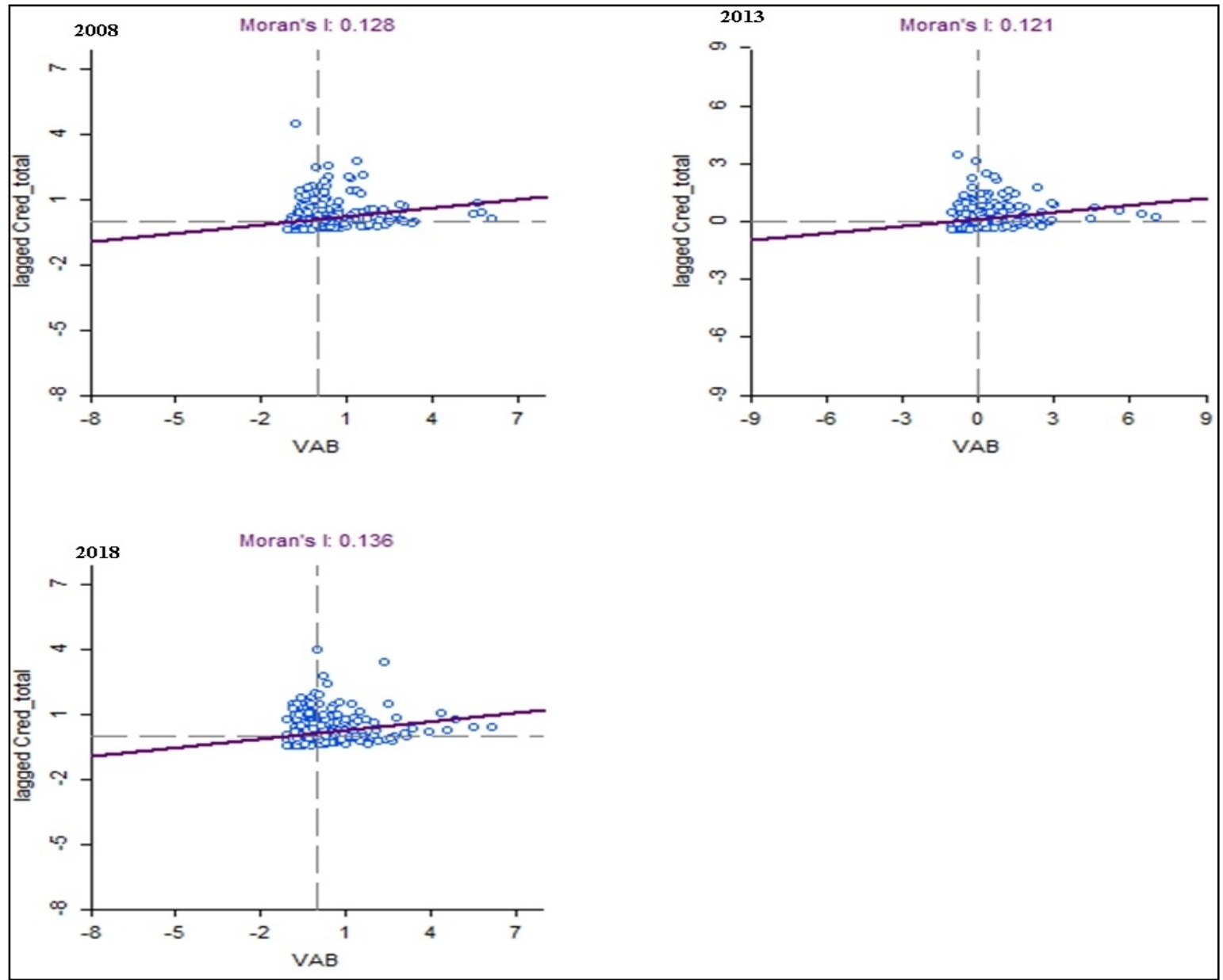

Fonte: Resultados da pesquisa.

O teste de pseudo-significância baseado em 999 permutações aleatórias indica nível de significância de 0,001 (99,9\% de probabilidade), assim a hipótese nula de que não existe autocorrelação espacial deve ser rejeitada. A próxima etapa consiste em avaliar os dados da dependência espacial de cada município com os valores do VAB e do crédito rural no período de análise, para isso, verifica-se o I de Moran Local Bivariado (Figuras 7, 8 e 9) para identificar os clusters do VAB e do crédito rural no Paraná. 
Figura 7 - I de Moran Local Bivariado, do Crédito Rural/VAB Agropecuário - 2008

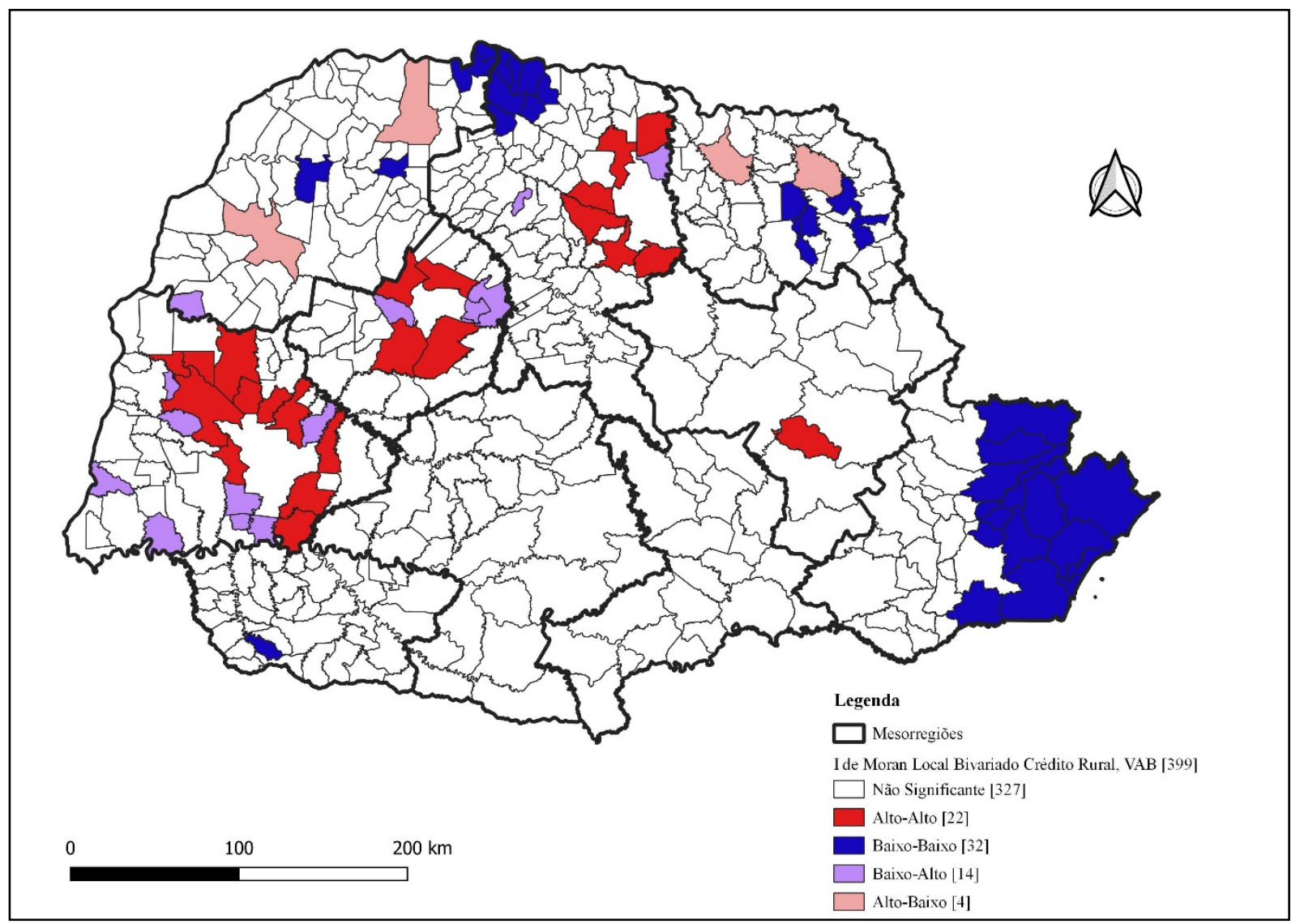

Fonte: Resultados da pesquisa.

A Figura 7 mostra os resultados das associações espaciais (clusters) para 2008, observa-se a formação de clusters nas mesorregiões Oeste, Centro-Ocidental, Norte-Central e Centro-Oriental como do tipo Alto-Alto, ou seja, esses municípios possuem altos valores no VAB e são vizinhos de municípios com alto valores no crédito rural, fato já evidenciado na Figura 3 e consolidado na correlação espacial. Foram identificados clusters Alto-Baixo, estão nas mesorregiões Noroeste e no Norte-Pioneiro, significa que esses munícipios possuem valores alto no VAB e seus vizinhos possuem baixa participação na distribuição do crédito rural. Foram identificados clusters Baixo-Alto, a maioria dessas associações apresentam-se na mesorregião Oeste Centro-Oriental, esses munícipios possuem baixa participação no VAB e seus vizinhos alta participação no crédito rural, essa situação pode ser justificada pela proximidade desses municípios com regiões onde existe forte atuação de empresas e cooperativas agroindustriais. Por fim, também identificou-se trinta e dois clusters BaixoBaixo, a maioria dessas associações localizam-se na mesorregião Metropolitana de Curitiba. 
Figura 8 - I de Moran Local Bivariado, do Crédito Rural/VAB Agropecuário - 2013

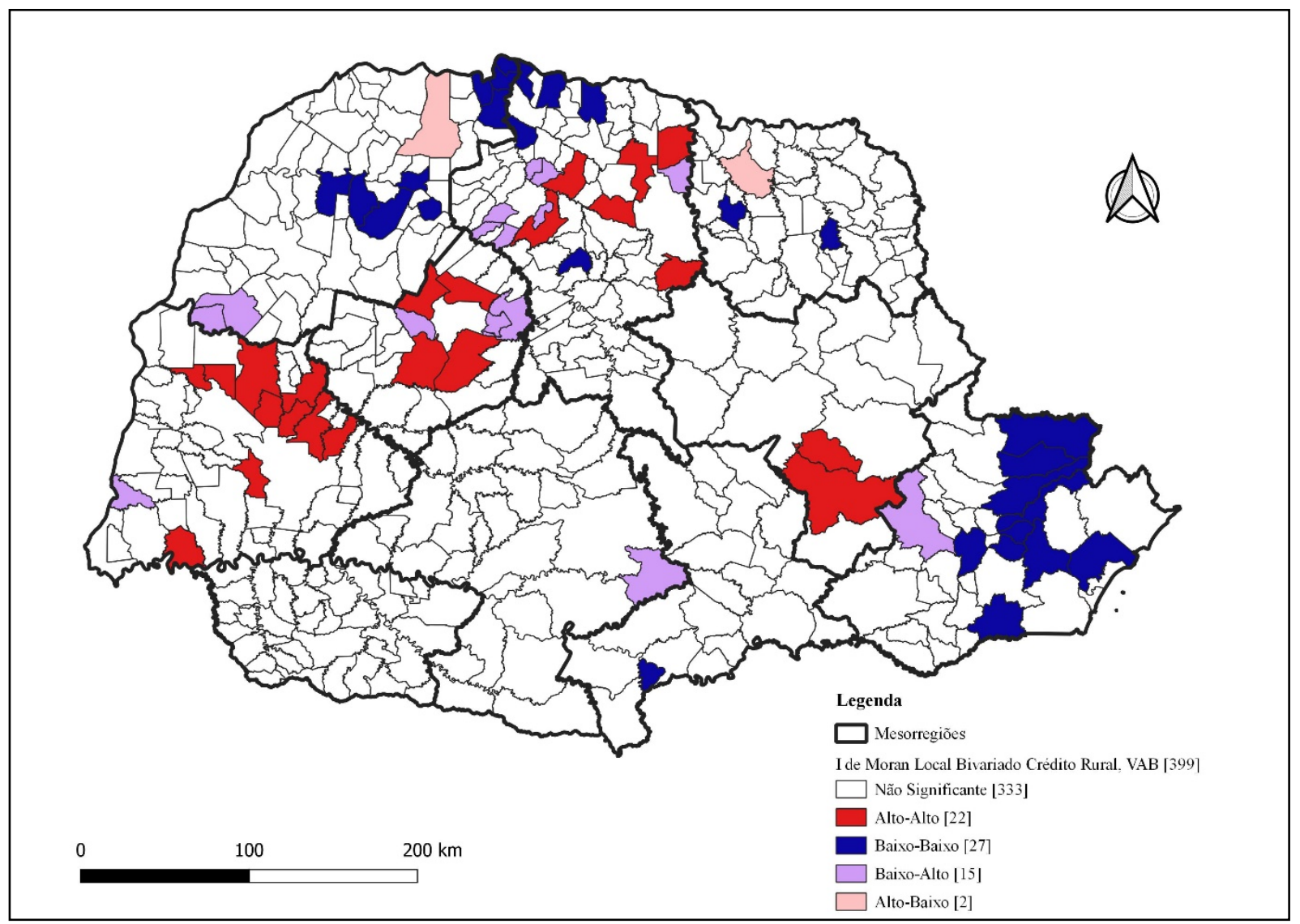

Fonte: Resultados da pesquisa.

Na Figura 8 apresentam-se os clusters identificados em 2013. Nota-se a formação de clusters Alto-Alto nas mesorregiões Oeste, Centro-Ocidental, Norte-Central e Centro-Oriental. As mesorregiões Noroeste e Norte-Pioneiro, os municípios de Paranavaí e Cornélio Procópio, apresentaram a formação Alto-Baixo, significa que possuem alto VAB e são vizinhos de municípios com baixos valores na concessão de crédito rural. Foram identificados clusters Baixo-Alto nas mesorregiões Oeste, Noroeste, Centro-Ocidental, Norte-Central, Centro-Sul e na Metropolitana de Curitiba, municípios com baixos valores no VAB e vizinhos de municípios com alto valor no crédito rural. Os clusters Baixo-Baixo concentram-se na mesorregião Metropolitana de Curitiba. 
Figura 9 - I de Moran Local Bivariado, do Crédito Rural/VAB Agropecuário - 2018

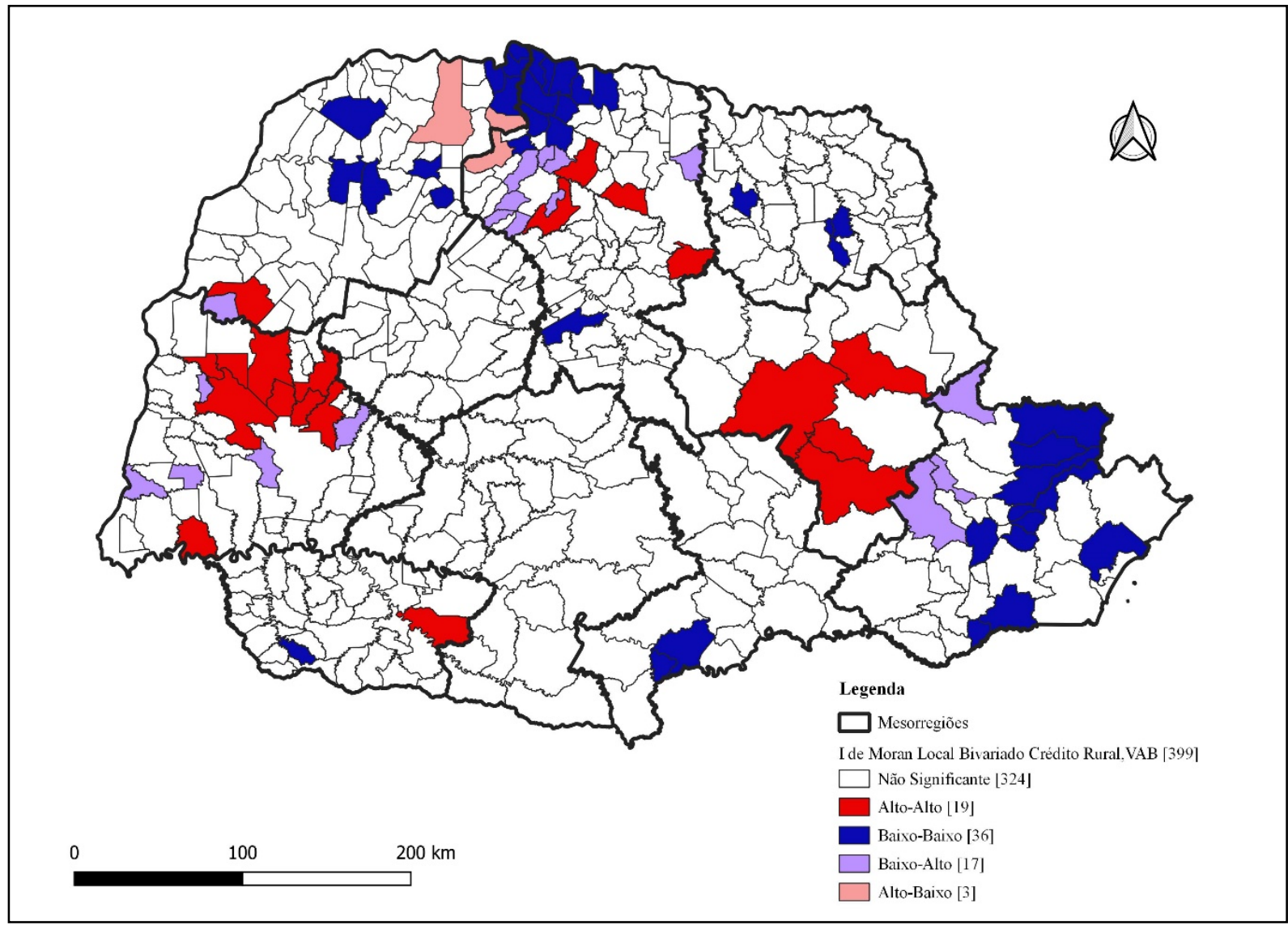

Fonte: Resultados da pesquisa.

Na Figura 9 verifica-se os padrões de associação espacial em 2018. Os clusters AltoAlto concentram-se nas Mesorregiões Oeste, Centro-Oriental, Norte-Central e no Sudoeste, evidencia-se a inclusão do Sudoeste. Foram identificados clusters Alto-Baixo nas mesorregiões Noroeste e Norte-Central. Nas mesorregiões Oeste, Norte-Central, Centro-Oriental e Metropolitana de Curitiba encontram-se os clusters Baixo-Alto. Os clusters Baixo-Baixo em maioria foram identificados na mesorregião Metropolitana de Curitiba, porém verifica-se associações entre municípios com baixos valores tanto no VAB quanto no crédito rural no Noroeste e Norte-Central.

\section{CONSIDERAÇÕES FINAIS}

O objetivo deste trabalho foi analisar a distribuição espacial do crédito rural em relação ao valor adicionado bruto pela agropecuária para os municípios do Paraná, através do Índice Regional do Crédito Rural (IRCR), para os anos de 2008, 2013 e 2018. Além disso, observouse a evolução da distribuição e as concentrações do crédito rural no estado. Por fim, verificouse a existência de correlação espacial do crédito rural em relação ao valor adicionado bruto da agropecuária, por intermédio da Análise Exploratória de Dados Espaciais (AEDE).

Os resultados do Índice Regional de Crédito Rural dos municípios mostraram desigualdades na distribuição do crédito rural, o qual concentrou-se entre os municípios que apresentam os maiores IRCR, entre eles Maringá, Londrina, Campo Mourão, Medianeira. Entre eles destacam-se a prevalência de propriedades ligadas as atividades agropecuárias,

Informe GEPEC, ISSN:1679-415X, Toledo, v. 26, n.1, p.87-105, jan./jun. 2022. 
empresas e cooperativas agroindustriais, Curitiba e Paranaguá, importantes cidades ligadas ao escoamento da produção agroindustrial do Paraná. Os munícipios com menores IRCR estão na região Metropolitana de Curitiba e litoral, esse resultado mostra que os municípios com menores IRCR possuem potencial para ampliar a demanda por crédito rural e dinamizar as atividades agropecuárias existentes. O IRCR para o Estado do Paraná apresentou tendência de queda, mesmo a região ampliando os valores do Valor Adicionado Bruto Agropecuário e do crédito rural, situação evidencia que a distribuição heterogênea do crédito rural pode estar limitando o potencial de crescimento das atividades agropecuárias.

A Análise Exploratória de Dados Espaciais (AEDE) foi complementar e apresentou autocorrelação positiva, identificando associações espaciais entre os municípios nas principais regiões ligadas a agropecuária do Paraná. Os resultados indicam que os municípios com altos valores no Valor Adicionado Bruto agropecuária são vizinhos de municípios com altos valores no crédito rural, destaque para as mesorregiões Oeste, Centro-Ocidental, Norte-Central, Centro-Sul e Centro-Oriental.

Os resultados possibilitaram o mapeamento da distribuição do crédito rural em relação ao valor adicionado bruto da agropecuária dos 399 municípios do Paraná. Contudo, alguns entraves foram identificados referentes aos dados do crédito rural, pois foram utilizados os valores totais sem nenhuma desagregação, sugere-se analisá-lo por programas específicos ou por finalidades de custeio, investimento, apoio à comercialização e à industrialização.

\section{REFERÊNCIAS}

ALMEIDA, E. Econometria espacial aplicada. Campinas: Editora Alínea, 2012.

BACHA, C. J. C. Economia e política agrícola no Brasil. 2. ed. São Paulo: Atlas, 2012.

BCB - BANCO CENTRAL DO BRASIL. Definições, Conceitos e Esclarecimentos sobre Crédito Rural. 2021a. Disponível em: https://bit.ly/3DB88PC. Acesso em: 5 jan. 2021.

BCB - BANCO CENTRAL DO BRASIL. Anuário Estatístico do Crédito Rural (2008 a 2012). 2021b. Disponível em: https://bit.ly/3yveFrm. Acesso em: 5 jan. 2021.

BCB - BANCO CENTRAL DO BRASIL. Matriz de dados do crédito rural (2013 a 2018). 2021c. Disponível em: https://bit.ly/3ysNyNn. Acesso em: 5 jan. 2021.

BELIK, W.; PAULILLO, L.F. Mudanças no financiamento da produção agrícola brasileira. 2001. Disponível em: https://bit.ly/3BKBt8k. Acesso em: 05 jan. 2021

BRASIL. Lei no 4.829 , de 5 de novembro de 1965. Institucionaliza o crédito rural. Brasília, DF, 1965.

BRASIL. Decreto no 1.946, de 28 de junho de 1996. Cria o Programa Nacional de Fortalecimento da Agricultura Familiar - PRONAF, e dá outras providências. Brasília, DF, 1996.

CAPUCHO, T. O.; PARRÉ, J. L. Produção leiteira no Paraná: um estudo considerando Informe GEPEC, ISSN:1679-415X, Toledo, v. 26, n.1, p.87-105, jan./jun. 2022. 
os efeitos espaciais. Informe Gepec, v. 26, n. 1, p. 112-127, 2012.

CROCCO, M. et al. O Estudo do Gap Regional de Crédito e seus Determinantes, sob uma Ótica Pós-Keynesiana. Economia, v. 12, n. 2, p. 281-307, 2011.

FAVARETTO, L. et al. Distribuição Espacial do Índice Regional de Crédito Rural para as Microrregiões do Rio Grande do Sul (2000-2015). Desenvolvimento em Debate, v. 8, n. 2, p. 41-61, 2020.

GALEANO, E. A. V.; SILVA, A. E. S.; SOUZA, R. C. Índice regional de crédito rural nos municípios do Espírito Santo. Revista de Política Agrícola, v. 16, n. 4, p. 5070, 2017.

IBGE - INSTITUTO BRASILEIRO DE GEOGRAFIA E ESTATÍSTICA. Produto Interno Bruto: Valor adicionado bruto a preços correntes da agropecuária. 2021a. Disponível em: https://bit.ly/3jBe1Ex. Acesso em: 5 jan. 2021.

IBGE - INSTITUTO BRASILEIRO DE GEOGRAFIA E ESTATÍSTICA. Divisão regional do Brasil. 2021b. Disponível em: https://bit.ly/3Bs7iCT. Acesso em: 5 jan. 2021.

IBGE - INSTITUTO DE PESQUISA ECONÔMICA APLICADA. Preços IGP-DI Anual. Disponível em: https://bit.ly/38xC1Ca. Acesso em: 12 jan. 2021.

IPARDES - INSTITUTO PARANAENSE DE DESENVOLVIMENTO ECONÔMICO. Valor Adicionado Bruto, Participação e Taxa de Crescimento, segundo as Atividades Econômicas, no Paraná. Disponível em: https://bit.ly/3Bu2oFp. Acesso em: 12 jan. 2021.

MAPA - MINISTÉRIO DA AGRICULTURA, PECUÁRIA E ABASTECIMENTO. Crédito Rural. Disponível em: https://bit.ly/3mUUgcW. Acesso em: 12 jan. 2021.

ROCHA, G. A. P.; OZAKI, V. A. Crédito rural Histórico e panorama atual. Revista de Política Agrícola, v. 29, n. 4, p. 6-31, 2020.

SILVA, F. P. Financiamento da cadeia de grãos no Brasil: o papel das tradings e fornecedores de insumos. Dissertação (Mestrado em Desenvolvimento Econômico) - Campinas: Universidade Estadual de Campinas, 2012.

Submetido em 26/9/2021. Aprovado em 20/12/2021. 